\title{
ANÁLISIS DE LA REALIDAD VOCACIONAL
}

DOI: https://doi.org/10.52039/seminarios.v62i218.105

Benvenuto ItALo CASTELLANI*

\section{INTRODUCCIÓN}

El cuestionario sobre la realidad vocacional mandado a las Conferencias episcopales, presentaba una «plantilla-guía» para la lectura de la situación vocacional y la recogida de datos. Se pedía que se respondiera con brevedad y claridad, y a ser posible a partir de la reflexión común del grupo responsable de la pastoral vocacional en cada país.

Los «temas» propuestos en la plantilla eran: Cultura vocacional, Centro diocesano de pastoral vocacional, Plan nacional de pastoral vocacional, Implicación de los presbíteros, Acompañamiento vocacional, Relación con las otras pastorales, Nuevos desafíos vocacionales, Nuevas metodologías, Número de seminaristas, Organización nacional y otros posibles puntos de interés.

A este Cuestionario, enviado a las cincuenta y siete Conferencias episcopales nacionales, respondieron treinta y cinco. A partir de esos datos, voy a presentar brevemente cada región, poniendo el acento en los aspectos positivos y en las dificultades, añadiendo una reflexión sobre el posible desarrollo de la pastoral vocacional en el ámbito de cada región. Asimismo, concluyo señalando las fortalezas y las debilidades de la pastoral vocacional hoy, con alguna referencia a los instrumentos fundamentales de esta pastoral.

$Y$ a pesar de que no ha sido una tarea fácil, sobre todo debido al carácter heterogéneo de la documentación recibida y analizada, he intentado ofrecer una «fotografía», mejor aún, una «panorámica», de la realidad no tanto para descubrir las «luces y las sombras» de la pastoral vocacional en la Iglesia, sino para buscar «signos de esperanza» que ayuden a seguir caminando.

\section{LECTURA Y ANÁLISIS DE LOS «INFORMES» DE LAS REGIONES ECLESIÁSTICAS}

a) América septentrional: Estados Unidos y Canadá

De la Región eclesiástica, compuesta por Estados Unidos y Canadá, han respondido ambas naciones.

La pastoral vocacional y el compromiso concreto de difundir una «cultura vocacional» son prioridades de varias diócesis de esta zona.

* Benvenuto Italo Castellani es arzobispo de la diócesis de Lucca (Italia). 
Los Centros diocesanos de pastoral vocacional -normalmente presididos por un sacerdote que no está dedicado a tiempo pleno; en dos diócesis el responsable es un laico- están presentes en la mayor parte de las Iglesias locales. Su servicio específico, configurado de diferentes maneras en cada diócesis -desde "Oficina» a "Casas de discernimiento»-, está dirigido sobre todo a la formación de agentes pastorales, a la elaboración de "programas» de acompañamiento y discernimiento al servicio de parroquias, escuelas secundarias o colegios universitarios; en todos los casos, pretende la promoción de las vocaciones sacerdotales, mientras que habitualmente la promoción de las vocaciones de especial consagración está confiada al vicario para la Vida religiosa.

La Conferencia episcopal de Estados Unidos, por su parte, ha hecho la opción por la promoción de la pastoral vocacional unitaria, ocupándose de las vocaciones sacerdotales y a la vida consagrada.

La Celebración de la Jornada mundial de Oración por las vocaciones está muy extendida en todas las diócesis.

Los presbíteros, menos los más jóvenes, están más bien ausentes en el anuncio y acompañamiento vocacional de las jóvenes generaciones, especialmente en la oferta del servicio de la dirección espiritual.

La relación entre pastoral juvenil, pastoral de la enseñanza y pastoral vocacional es muy estrecha; en cambio, es casi nula con la pastoral familiar y social.

El mundo de la Comunicación social, en todas sus expresiones modernas, es considerado negativo por los fuertes condicionamientos de las jóvenes generaciones. Comienza a ser valorado, por su eficacia, el anuncio vocacional que se dirige e implica a los monaguillos, las familias y los ámbitos de la enseñanza católica.

A modo de síntesis: el signo y la senda para un posible desarrollo de la pastoral vocacional en esta región se pone de manifiesto en el compromiso por la difusión de una «cultura vocacional».

b) México, América Central y Caribe: México, Guatemala, Honduras, Nicaragua, Costa Rica, República Dominicana y Puerto Rico

De esta región eclesiástica han respondido el $63 \%$ de las Conferencias episcopales. No lo han hecho El Salvador, Panamá, Cuba y Haití.

La pastoral vocacional está encontrando gradualmente un contexto favorable para el desarrollo de una «cultura vocacional», hasta constituir incluso en algunas naciones el compromiso prioritario, especialmente mediante: la oración vocacional muy extendida en el pueblo de Dios, grupos específicos de oración por las vocaciones, valoración del pueblo de Dios de los presbíteros y los consagrados, la conciencia ampliamente difundida en las comunidades cristianas de la vocación bautismal personal. 
Buena parte de las diócesis cuenta establemente con un Centro diocesano de pastoral vocacional, que se configura normalmente como un equipo con representación de las distintas vocaciones (presbíteros, consagrados y fieles laicos) presidido o coordinado por un presbítero.

Su principal servicio, además de la animación vocacional de las comunidades parroquiales, está dirigido a la formación de animadores vocacionales mediante cursos específicos y, en algunos casos, sistemáticos.

Sólo algunas naciones tienen un plan nacional de pastoral vocacional, que promueve la relación entre pastoral vocacional, catequética, juvenil y familiar, mientras que la implicación de los presbíteros en la mayor parte de los casos encuentra poca respuesta.

Los retos que los planes pastorales nacionales existentes han subrayado van desde los compromisos por el desarrollo de la cultural vocacional hasta la dimensión vocacional de la pastoral ordinaria; llegar a los «nuevos areópagos» y garantizar la personalización del anuncio y la propuesta vocacional; lograr la formación de agentes vocacionales y favorecer un vínculo más profundo entre familia, ámbito educativo y vocaciones.

La insistencia generalizada en el anuncio y la propuesta vocacional entre las jóvenes generaciones ha provocado un lento pero constante aumento de las vocaciones presbiterales, mientas que se constata un descenso significativo de las vocaciones consagradas, tanto masculinas como femeninas.

Las Conferencias episcopales nacionales están casi todas organizadas con una Comisión, Consejo, Departamento o Centro nacional.

A modo de síntesis: el signo y la senda para un posible desarrollo prometedor de la pastoral vocacional en esta Región se puede percibir en el plano educativo de las jóvenes generaciones en clave vocacional.

\section{c) Norte de Sudamérica: Colombia, Ecuador, Bolivia y Venezuela}

De esta región eclesiástica no han enviado respuesta Bolivia ni Venezuela.

La pastoral vocacional es considerada como una prioridad: la «dimensión vocacional» de la vida en la mayor parte de los planes pastorales diocesanos está cada vez más presente en el proceso de evangelización.

Cabe destacar los itinerarios vocacionales promovidos por las diócesis, que promueven a la vez la «cultura vocacional» y la evangelización en clave vocacional: por ejemplo, la semana vocacional, el día del seminario, la escuela de la fe, la promoción de grupos de monaguillos, semanas intensivas anuales para la formación de agentes vocacionales y especialmente la oración por las vocaciones, en las que colaboran las comunidades contemplativas.

Todas las diócesis tienen un Centro vocacional diocesano que, como se indica expresamente, «trabaja prácticamente sólo por las vocaciones presbiterales»; cada año se organiza a nivel nacional un Encuentro formativo para 
los agentes pastorales, cuyo objetivo es sensibilizar en la dimensión vocacional de la pastoral ordinaria y en el anuncio específico de las vocaciones al ministerio ordenado y de especial consagración.

Se está elaborando o actualizando el Plan nacional de pastoral vocacional o el Directorio nacional de pastoral vocacional. Se constata la escasa sensibilidad y preparación en el campo de la pastoral vocacional de los presbíteros, si bien los más jóvenes se muestran más disponibles.

La pastoral de las vocaciones se percibe como un «sector independiente», aunque una «pastoral integrada» se ve como una necesidad cada vez mayor.

El reto ante el cual se encuentra el anuncio del «Evangelio de las vocaciones» es el siguiente: de un proceso vocacional dirigido a jóvenes practicantes de la comunidad cristiana a una "pastoral vocacional en salida», con la propuesta de «encuentros vocacionales parroquiales» dirigidos especialmente a todos los adolescentes.

El número de las admisiones en el seminario tiende a aumentar en algunas naciones y a disminuir en otras: en todas las Iglesias se presta cada vez más atención al discernimiento vocacional para garantizar mayor perseverancia.

No todas las naciones cuentan con el servicio del Centro nacional vocacional o del Equipo nacional de coordinación.

A modo de síntesis: el signo y la senda para un posible desarrollo de la pastoral vocacional se puede percibir en el cuidado e implementación de «itinerarios vocacionales» en la pastoral ordinaria.

\section{d) Sur de Sudamérica: Chile, Uruguay, Paraguay, Perú y Argentina}

De esta región eclesiástica respondieron todas las naciones menos Brasil.

Por lo que respecta a la promoción de la «cultura vocacional», la situación es desigual: en Chile y Paraguay han hecho de ella la finalidad principal en la vida de los creyentes y de la comunidad cristiana; en Perú se constata una creciente sensibilidad vocacional, mientras que en Argentina la cultura vocacional representa un reto.

La opción por una cultura vocacional se ha concretado en la oferta de una formación sistemática de los agentes pastorales, la realización del Mes vocacional, además de la implementación de Itinerarios vocacionales para jóvenes, organizados en dos etapas: «despertar» $\mathrm{y}$ «discernir», promoviendo el acompañamiento vocacional personal (Uruguay).

Los Centros diocesanos vocacionales como tales, bajo la dirección de un presbítero que se ocupan prioritariamente del anuncio de la vocación sacerdotal, están presentes en la mayoría de las diócesis de Paraguay y en todas las de Uruguay. Con la modalidad de un «equipo» bajo la guía de un presbítero diocesano, están presentes en la totalidad de las diócesis de Perú y en dos tercios de las de Chile. 
Falta un auténtico Plan nacional de pastoral vocacional: se encuentra en proceso de elaboración en Chile y en Perú. En esta última, para responder a la gran diversidad cultural del país, se elabora anualmente una Guía metodológica vocacional para marcar un camino unitario.

A los presbíteros les cuesta responsabilizarse de la pastoral vocacional: en Perú, la publicación de la Guía metodológica anual facilita la sensibilización; no están bien preparados o bien dispuestos para llevar adelante el servicio de acompañamiento en Argentina. Sólo los presbíteros encargados de la pastoral vocacional en las diócesis son más sensibles y están capacitados para ofrecer acompañamiento vocacional personal.

La relación entre pastoral vocacional y pastoral de los adolescentes o de los jóvenes es fuerte en Chile -donde llegan a celebrar congresos nacionales conjuntamente- y en Uruguay. Es más difícil la relación con la pastoral familiar y de la enseñanza en todos estos países.

Se constata un descenso de las vocaciones presbiterales -incluso con el cierre de algunos seminarios- y para la vida consagrada. Únicamente Uruguay mantiene una cierta estabilidad, con un significativo incremento de las vocaciones a la vida contemplativa.

Sería deseable una organización más eficaz de la pastoral vocacional en Chile -donde no existe Centro nacional vocacional, sino una Comisión episcopal de pastoral vocacional-; un Centro nacional marca las líneas fundamentales de pastoral vocacional en Paraguay; en Uruguay hay un Departamento para las vocaciones y los ministerios; una Comisión episcopal se ocupa de organizar tres eventos anuales en Perú: la Jornada mundial de oración por las vocaciones, el Encuentro de rectores y de formadores de seminarios.

Los retos ante los cuales se encuentra la pastoral vocacional en esta región son: la formación adecuada de los agentes de pastoral vocacional, el desarrollo de los centros diocesanos de vocaciones, un anuncio vocacional capilar en las comunidades cristianas, la evangelización de las familias, una valoración adecuada de los medios de comunicación.

A modo de síntesis: el signo y la senda para un posible desarrollo de la pastoral vocacional en esta región se puede percibir en el incremento de la formación de los agentes pastorales y en el desarrollo de los centros diocesanos vocacionales.

\section{e) Australia y Asia: Australia y Filipinas}

De esta región eclesiástica han llegado la totalidad de las respuestas.

Se constata, en una región con áreas geográficas y culturales muy diversas. Algunas características son:

-Una fuerte cultura vocacional, sobre todo en el ámbito rural, en Filipinas, y un significativo desarrollo en Australia. 
- La presencia de centros diocesanos vocacionales, que se ocupan de todas las vocaciones consagradas en Filipinas, y un fortalecimiento de los mismos en Australia.

-No hay un auténtico Plan nacional de pastoral vocacional, al menos en Filipinas, pero en el ámbito nacional, se ofrece un itinerario formativo completo para los agentes de pastoral vocacional; y además se organiza un Congreso y un encuentro de directores de los centros diocesanos vocacionales cada dos años.

-En Filipinas, los presbíteros tienen una cierta sensibilidad vocacional, pero no se atreven a llamar explícitamente, algo a lo que son más sensibles las familias.

- La relación entre pastoral vocacional y juvenil es buena; con la pastoral familiar, incipiente; pero prácticamente nula con las otras pastorales.

-El desarrollo de los medios de comunicación, que de hecho condiciona a las jóvenes generaciones en sus opciones vocacionales, es relativamente utilizado en la pastoral vocacional con propuestas específicas. El testimonio vocacional de sincera adhesión al Evangelio por parte de presbíteros y consagrados sigue siendo el medio insustituible para el anuncio vocacional.

-A la explosión de vocaciones en Filipinas, en estos momentos en disminución en las grandes ciudades, se corresponde un cierto aumento de incorporaciones en los seminarios de Australia.

-Sería deseable mayor inversión económica para la actividad vocacional en Filipinas y una mayor formación por parte de los presbíteros en la pastoral vocacional al servicio de todas las vocaciones.

A modo de síntesis: el signo y la senda para un posible desarrollo de la pastoral vocacional en esta región se puede percibir en la toma de conciencia de la necesidad de un anuncio vocacional explícito por parte de los presbíteros y consagrados implicados en la pastoral ordinaria de la vida de las comunidades cristianas.

f) Europa occidental: España, Italia, Inglaterra, Escocia, Bélgica, Irlanda, Malta, Portugal

De esta región eclesiástica únicamente no ha respondido Francia.

La región presenta una situación diferenciada en las distintas naciones.

-En algunas existe una incipiente promoción de la cultura vocacional (España, Irlanda, Italia, Escocia, Malta), mientras que en otras está ausente.

-En algunas existen auténticos «centros diocesanos de vocaciones» (España, Italia), normalmente obra de los seminarios diocesanos y dirigidos al anuncio de la vocación presbiteral; en otras existe un "equipo» con representación de todas las vocaciones consagradas (Irlanda), o una «oficina diocesana» para las vocaciones (Escocia), un «secretariado diocesano» que se 
ocupa de todas las vocaciones (Portugal), un «sacerdote encargado» que -ayudado por una pareja de laicos- se ocupa del anuncio únicamente de la vocación al presbiterado (Malta).

-En algunas existe un auténtico Plan nacional de pastoral vocacional (Inglaterra e Italia, si bien en esta última necesita una actualización, pues es de 1985); en otras el Plan se encuentra en fase de elaboración (Irlanda y Escocia); en otras no existe (España, Bélgica, Malta); y Portugal hay un Documento para la pastoral vocacional que da orientaciones para los programas diocesanos de pastoral vocacional.

-En toda la región se constata una notable sensibilidad -que lleva consigo una cierta implicación y dedicación a la pastoral vocacional-, si bien en grados diversos: esta dedicación se refiere sobre todo al crecimiento humano y espiritual de los jóvenes, mientras que se constata un cierto cansancio de los presbíteros en la escucha, acompañamiento y, específicamente, en el servicio de dirección espiritual personal de las jóvenes generaciones.

-El acompañamiento vocacional propiamente dicho se ofrece a los jóvenes, en primera instancia, por parte de los párrocos más sensibilizados $y$, posteriormente, es confiado a los formadores del seminario (España); es realizado por grupos específicos de acompañamiento vocacional: los «grupos Samuel» (Bélgica); con el ofrecimiento de un itinerario más articulado: con el programa «Samuel» para un primer acompañamiento básico, el programa «Vianney» para la propuesta de la vocación presbiteral y el programa «Compass» para la vocación religiosa (Inglaterra); por grupos vocacionales que ponen en el centro la Palabra de Dios y la dirección espiritual, ejercicios espirituales y experiencias de servicio (Italia); desde una dirección espiritual específica (Escocia) y un itinerario de descubrimiento vocacional con un «pre-seminario» (Portugal), al ofrecimiento de una acompañamiento adecuado (Malta).

-La relación con la pastoral juvenil -y en algunas naciones también con la pastoral familiar- es muy estrecha y es un trabajo en curso.

-Entre los nuevos retos vocacionales -además de la sociedad secularizada y la indiferencia religiosa-, el más significativo es la urgencia de un cambio de «lenguaje» en "palabras clave» de la pastoral: convocatoria, formación, animación, comunicación, fraternidad...

-Entre las nuevas metodologías -si bien sigue siendo prioritaria y esencial la relación personal y la dirección espiritual- se constatan estas vías: ejercicios espirituales, periodos de vida común, peregrinaciones, presencia en los medios de comunicación.

-Los nuevos ingresos en los seminarios diocesanos en estos últimos años se han estabilizado un poco en todas las diócesis, pero mantienen números demasiado bajos. En claro descenso, prácticamente generalizado, las vocaciones de especial consagración masculinas y femeninas. 
-La Organización nacional de la pastoral vocacional en un Centro nacional de pastoral vocacional tiene una larga y activa historia en la Iglesia italiana, y una presencia y un servicio en aumento en las otras naciones.

A modo de síntesis: el signo y la senda para un posible desarrollo de la pastoral vocacional en esta región se puede percibir en la intensificación del compromiso en la propuesta de Itinerarios vocacionales comunitarios, junto con el acompañamiento personalizado en la dirección espiritual.

\section{g) Europa central: República Checa}

Únicamente ha respondido la República Checa de las diecisiete naciones interpeladas en esta región eclesiástica.

En esta nación existe ya desde hace tiempo el interés por crear una «cultura vocacional», particularmente por la actividad de casi diez años del Equipo vocacional nacional, que realiza su servicio con la colaboración de todas las vocaciones.

La dedicación del servicio nacional no encuentra correspondencia en la creación de un Centro de pastoral vocacional en cada diócesis. El anuncio vocacional -siempre bajo la orientación del Equipo nacional- está abierto a todas las formas de vida consagrada y, desde 2011, se ha elaborado un Plan pastoral nacional para la pastoral vocacional.

El cuidado de las vocaciones, a pesar de ser «connatural» al ministerio presbiteral, lo prestan sobre todo aquellos que se sienten felices con su vocación, faltando así buenos acompañantes vocacionales. Existe y funciona bien el vínculo con las otras acciones pastorales.

Los nuevos retos vocacionales a los que se enfrenta el servicio de la pastoral vocacional son los siguientes: promover el espíritu de oración; iniciar cursos y encuentros para los animadores vocacionales; dar a conocer los nuevos impulsos del magisterio de la Iglesia; crear espacios para la expresión de los jóvenes; presentar las vocaciones específicas que son un don de Dios a la Iglesia; promover la pastoral vocacional en las escuelas; promover el anuncio de todas a las vocaciones, desde el presbiterado a las vocaciones de especial consagración.

Las nuevas metodologías usadas son: la distribución de un folleto para la Semana vocacional, preparación de coordinadores, intervenciones más frecuentes en los medios de comunicación, jornadas vocacionales parroquiales, encuentros vocacionales con jóvenes, participación en las iniciativas de la pastoral juvenil, jornadas de puertas abiertas en los seminarios y casas religiosas.

A pesar del fuerte compromiso que se constata sobre todo en el ámbito nacional -que tiene un momento fuerte en la preparación del encuentro anual de coordinadores- el número de candidatos al presbiterado ha descendido. 
A modo de síntesis: el signo y la senda para un posible desarrollo de la pastoral vocacional en esta región se puede percibir en el convencimiento de la importancia del anuncio a la comunidad cristiana de todas las vocaciones, desde la presbiteral a las vocaciones de especial consagración, que florecen a partir de la conciencia de la llamada común a la santidad.

\section{h) Europa Oriental: Polonia, Lituania, Eslovaquia, Eslovenia}

De esta región eclesiástica han respondido la mitad de las naciones, no enviando contestación Estonia, Bielorrusia, Ucrania, Kazajistán, Rusia.

En esta región la «cultura vocacional» es sinónimo de «sensibilidad y sensibilización» del pueblo de Dios con la oración por las vocaciones sacerdotales: específicamente la adoración eucarística (Eslovaquia) y grupos de oración (Lituania). En Polonia, a propósito de la oración por las vocaciones, «se empieza a hablar, si bien tímidamente, no sólo de la vocación sacerdotal, sino también de las vocaciones consagradas».

El servicio del Centro diocesano de vocaciones está presente en casi todas las diócesis -en Lituania lo llevan los seminaristas-y se configura como oficina vocacional, comisión vocacional, equipo vocacional. Polonia subraya que solo «tres diócesis tienen un equipo para todas las vocaciones», para indicar que la orientación es la del anuncio no sólo de las vocaciones presbiterales, sino también de las consagradas.

Por el momento, los planes pastorales nacionales se encuentran en proceso de elaboración. Sólo Eslovaquia lo ha elaborado inspirándose en el documento Nuevas vocaciones para una nueva Europa.

La implicación de los presbíteros en la pastoral vocacional encuentra buena respuesta y apoyo en todas las naciones: les falta formación para el acompañamiento o, allí donde se ofrece, se realiza en el ámbito del sacramento de la confesión, la dirección espiritual y los ejercicios espirituales, así como en el encuentro personal de los jóvenes en búsqueda vocacional directamente con el obispo.

Hay una fuerte relación-con acentos diversos de nación a nación- sobre todo con la pastoral juvenil, pero también con la universitaria, la catequesis, la pastoral familiar y la pastoral con los monaguillos.

La crisis de la familia (Polonia), el descenso de la natalidad (Lituania), junto con la dificultad de la exigencia de una espiritualidad profunda, son los mayores retos del momento presente a la pastoral vocacional.

La multiforme creatividad de las diócesis en cada nación pone en práctica nuevas tecnologías de anuncio, propuesta y acompañamiento vocacional, entre ellas: «Seminarios abiertos» durante una jornada (Polonia), Programa de maduración integral «Ven y verás» (Eslovenia), «Servicio de la escucha» por parte de los consagrados (Eslovaquia), «Ejercicios espirituales» (Lituania). 
En los últimos diez años, se constata una disminución general del número de seminaristas en todas las naciones, a excepción de Eslovenia, donde ha aumentado.

La organización nacional de la pastoral vocacional cuenta con un auténtico Centro nacional vocacional (Eslovaquia), un Consejo nacional (Polonia), una Comisión interdiocesana (Eslovenia), mientras que en Lituania no hay nada constituido.

A modo de síntesis: el signo y la senda para un posible desarrollo de la pastoral vocacional en esta región se puede percibir en el compromiso adicional por una «cultura vocacional» que, desde la oración, se abra a itinerarios que promuevan un crecimiento humano integral de la persona.

\section{i) Europa balcánica: Albania, Croacia, Rumanía, Hungría}

En esta región eclesiástica han respondido la mitad de las naciones, siendo excepción Bosnia, Herzegovina, Serbia y Bulgaria.

Se constata una diversidad natural debida a la reciente historia comunista de estos países. El desarrollo de una cultura vocacional en la región se presenta con una gran diversidad.

La cultura vocacional se ha desarrollado en Croacia; con una notable diferencia entre las zonas urbanas y rurales, en Rumanía; débilmente en Albania; ambigua en Hungría.

Los centros diocesanos de pastoral vocacional -con denominaciones diversas- están presentes en número significativo en Albania y Croacia y, no en todas las diócesis, en Hungría y Rumanía.

No existe -más allá de un proyecto unitario entre las varias realidades implicadas en el campo educativo juvenil en Hungría- Plan pastoral nacional para las vocaciones.

Los presbíteros demuestran una adecuada sensibilidad (Albania), y su implicación es significativa en aquellas diócesis donde hay seminario (Rumanía), entre los presbíteros comprometidos con el servicio de la caridad (Hungría) y en las parroquias dirigidas por religiosos (Croacia).

El acompañamiento vocacional de los jóvenes está bien organizado por los seminarios en Hungría y Rumanía, mientras que requiere mayor desarrollo en Albania y Croacia.

La relación de la pastoral vocacional con las otras pastorales, en especial la juvenil y la de la enseñanza, existe en Albania; debe ser reforzada en Hungría; es estrecha en Rumanía, y está poco desarrollada en Croacia.

Nuevas metodologías -junto a las ya experimentadas como el acompañamiento vocacional personal y de grupos (Albania) - son las siguientes: evangelización de calle (Croacia), vídeo o página web del seminario (Hungría). Se apoya la inserción de la pastoral vocacional en los lugares virtuales (Rumanía). 
El número de los candidatos al presbiterado está en aumento en Croacia, es estable en Hungría, disminuye en Rumanía, desciende con respecto al florecimiento vocacional y pastoral registrado tras la caída del régimen comunista en Albania.

Junto a un aumento también de las vocaciones a la vida religiosa masculina y a la vida contemplativa femenina en Croacia, se constata una bajada gradual de los candidatos a la vida religiosa masculina y aún más a la femenina de vida activa en Hungría.

La Organización nacional de la pastoral vocacional existe bajo la forma de Centro nacional vocacional en Albania y Hungría, y como Comisión episcopal para todas las vocaciones en Croacia.

Algunas Naciones advierten la necesidad de compartir su experiencia sobre Pastoral de las vocaciones con otras naciones de su misma región y de otras regiones.

A modo de síntesis: el signo y la senda para un posible desarrollo de la pastoral vocacional en esta región se percibe en la preparación del Plan pastoral para las vocaciones, como ocasión para difundir una «cultura vocacional» y para formar educadores y agentes pastorales en una «conciencia vocacional».

\section{FoRTALEZAS Y DEBILIDADES DE LA PASTORAL VOCACIONAL HOY}

Del análisis de la realidad vocacional surgen algunas fortalezas y debilidades de la pastoral vocacional que hemos de recibir como «indicadores» de un camino hacia delante.

a) Aspectos culturales y motivos teológicos inspiradores de la pastoral vocacional

La acción pastoral de la Iglesia se encuentra hoy ante una «especie de cultura antivocacional», de manera que se puede hablar de «un hombre sin vocación» ${ }^{1}$.

En nuestros días, además del problema del número, está en juego el modo de concebir la vida y también la calidad de un camino de fe eclesial y personal.

Para el desarrollo de una "cultura vocacional difusa» y para un anuncio vocacional eficaz, son ineludibles dos interrogantes de base.

1) ¿Qué concepto de la vida?

Hoy los cristianos están llamados a aprender de la más genuina interpretación bíblica de la vida: la vida es desde su comienzo «llamada a existir», y

1. Obra pontificia para las vocaciones eclesiásticas, Nuevas vocaciones para una nueva Europa, $11 \mathrm{c}$. 
el descubrimiento y la respuesta a la propia vocación permite al hombre llegar a un encuentro personal con Dios y realizar así su destino plenamente. Sin embargo, este modo de concebir la vida se encuentra hoy expuesto a una cultura en la que la perspectiva de una vocación divina resulta prácticamente ajena al horizonte de la existencia. Estamos ante un desafío cultural sobre la concepción de la vida.

En el intento de la comunidad cristiana de «evangelizar la vida», una categoría bíblica fundamental y urgente a descubrir y retomar es la de la «elección divina», es imprescindible evangelizar la libertad. En la Palabra de Dios se funda una idea alta y fuerte de la libertad del hombre. Para el hombre, acoger y seguir la propia llamada quiere decir llegar a ser más auténticamente libre. También estas verdades, a menudo olvidadas, hacen hoy de la pastoral vocacional una escuela de promoción de la libertad.

2) ¿Qué motivos teológicos inspiran la pastoral vocacional?

El primer motivo teológico, que desde siempre ha inspirado la pastoral vocacional, es el siguiente: «Toda vida es vocación». Se trata de una verdad teológica cuyo significado deriva directamente de la fuente bautismal y nos recuerda «la llamada universal a la santidad».

El segundo motivo teológico inspirador de la pastoral vocacional es la concepción de la «fe como encuentro con Cristo». La experiencia cristiana parte de la iniciativa exclusiva de Dios, crece en el contexto de Alianza y espera una respuesta. Promover una acción pastoral quiere decir propiciar este encuentro concreto y decisivo con Jesucristo, que por su naturaleza lleva consigo proyectar la propia vida a partir de la voluntad de Dios.

El tercer motivo teológico que fundamenta la pastoral vocacional es que el hombre ha sido creado «a imagen de Dios-Trinidad». El cristiano lleva en su vida y testimonia en el mundo la imagen inconfundible de la Santa Trinidad, a cuya semejanza ha sido creado. Concretamente, su relación con el Padre configura su vida en una actitud filial cada vez más madura y en la conciencia de ser amado: una postura con relación a la vida decisiva para poder amar.

Por último, el cuarto motivo inspirador es la «eclesialidad» de la vocación cristiana. Toda vocación nace en un contexto preciso, concreto y forma parte de la Iglesia.

\section{b) Sendas esenciales de la Pastoral ordinaria vocacional}

Recojo aquí las «sendas» ordinarias que se han puesto de manifiesto en el análisis anterior y que de hecho cualifican vocacionalmente la vida de la Comunidad cristiana: la oración, el anuncio, el testimonio, el acompañamiento educativo. 


\section{1) La oración por las vocaciones}

Por este camino se llega al corazón de Dios. La vida del hombre, como vocación, discurre toda ella entre la gracia y la libertad. La oración es lo único que puede actuar en ambos lados de la vocación, que son la gracia (Dios que llama) y la libertad (el hombre que responde).

Oración y gracia: la oración obtiene la gracia de la vocación. Actúa en la fuente misma de la vocación.

Oración y libertad: la oración influye en la libertad del hombre, en cuanto posibilita su respuesta a la llamada de Dios.

En este sentido la oración y la oración por las vocaciones es «centro de toda la pastoral vocacional»².

Algunas propuestas prácticas de «oración por las vocaciones» son:

-Escuela de oración, especialmente para los jóvenes.

- «Monasterio invisible», compromiso de oración-penitencia personal.

-Adoración, encuentros y vigilias de oración; por grupos o para la comunidad.

-El primer jueves de mes para las vocaciones en la parroquia; adoración-ayuno.

-La celebración de la Jornada mundial de oración por las vocaciones.

\section{2) El anuncio}

La pastoral ordinaria en "clave vocacional». El itinerario catequético, litúrgico, caritativo y ministerial sigue siendo en la comunidad cristiana la propuesta educativa fundamental y esencial para la fe y la vocación de todo bautizado.

Los elementos constitutivos de la Iglesia -Palabra, sacramentos, caridadcorrespondientemente traducibles por catequesis (Itinerario de escucha de la Palabra), liturgia (Itinerario litúrgico sacramental) y testimonio de la caridad (Itinerario ministerial y del servicio de la caridad) no pueden, por tanto, ser vividos en la Comunidad cristiana sino en clave vocacional.

La resonancia vocacional constitutiva de la pastoral juvenil: «complementariedad» de la pastoral juvenil y vocacional. La pastoral juvenil es completa y eficaz cuando se abre a la dimensión vocacional y la pastoral específica de las vocaciones encuentra en la pastoral juvenil su espacio vital ${ }^{3}$.

Especificidad de la pastoral vocacional: anuncio, propuesta y acompañamiento de las vocaciones al ministerio ordenado y de especial consagración. La pastoral vocacional no es uno de los «sectores» o «ámbitos» de la pastoral: es la forma y el alma de todas las pastorales, por lo cual se puede

2. Juan Pablo II, Pastores dabo vobis, 34.

3. Cf. Obra pontificia para las vocaciones eclesiásticas, Nuevas vocaciones para una nueva Europa, 2. 
hablar de «animación vocacional y anuncio de las vocaciones particulares y específicas que son don de Dios a la Iglesia.

Los Organismos eclesiales unitarios de referencia. Los centros diocesanos de vocaciones, y el Centro nacional de vocaciones expresan el compromiso de la Iglesia por el estudio, la animación y la coordinación de la pastoral vocacional.

Algunas propuestas prácticas de «anuncio» en la pastoral ordinaria vocacional son:

-Catequesis (niños, adolescentes, jóvenes) en clave vocacional.

- La celebración del sacramento del perdón y de la eucaristía en el contexto del año litúrgico (el «mes vocacional»).

-Toda expresión de servicio ministerial en la comunidad cristiana, como lugar educativo al don de sí (la propuesta de los «ministerios de hecho», el servicio a los pobres, el voluntariado).

- Itinerarios específicos de acompañamiento personalizado y comunitario de los jóvenes en proceso de discernimiento vocacional.

\section{3) El acompañamiento}

El servicio de dirección espiritual, al servicio de la orientación y acompañamiento vocacional. En un camino de crecimiento en la fe y vocacional, el acompañamiento individual, personalizado mediante el discernimiento y la dirección espiritual cualificadamente realizados, es complementario y coesencial junto al acompañamiento comunitario en el camino compartido y gradual de fe de un grupo.

La dirección espiritual -como mediación de una persona adulta en la experiencia de fe y eclesial en el camino de maduración espiritual de la persona y de discernimiento vocacional- ofrece este servicio: libera a la persona, sobre todo a los jóvenes, de los riesgos del subjetivismo; ayuda a concretizar intuiciones o aspiraciones ideales; propone contenidos motivadores; abre el corazón y la vida a los signos mediante los cuales habla Dios; previene y educa al joven a gestionar los momentos ineludibles de crisis; se propone como verificación del camino de crecimiento global de una persona.

\section{4) El testimonio}

Los educadores en la fe cristiana como "animadores vocacionales nativos»: el testimonio gozoso de la vocación. Este compromiso es apremiante para aquellos que en la comunidad cristiana viven una vocación al ministerio ordenado o de especial consagración -junto a las familias cristianas y a todos los animadores de pastoral juvenil-, cada uno con sus propios dones.

A ellos se les confía, a partir de su testimonio, el anuncio del «Evangelio de la vocación». 
Algunas de las propuestas prácticas que se pueden sugerir para la formación vocacional de los educadores en la fe nativamente educadores vocacionales son las siguientes:

-Padres: catequesis prebautismal de los hijos; preparación para los sacramentos de la iniciación cristiana; itinerarios vocacionales para novios; preparación remota y próxima para el matrimonio: «grupos familias».

-Catequistas: preparación del catequista, ya de por sí «animador vocacional», en las escuelas de catequistas.

-Animadores de grupos, movimientos, asociaciones: conscientes de proponer y promover un itinerario de fe en clave y en perspectiva vocacional.

-Animador vocacional parroquial: una figura laica que en la parroquia asume el servicio de hacer presente en todas sus actividades la animación vocacional.

\section{CONCLUSIONES}

A modo de síntesis, en el espíritu que debe caracterizar cada vez más la pastoral vocacional entendida como «acción coral» de toda la comunidad eclesial, propongo el presente decálogo sobre el «Estado adulto y maduro de la pastoral vocacional».

1. Una «pastoral de la maternidad»: de la emergencia a la coherencia. Dios sigue generando vida.

2. Una pastoral para todas las vocaciones: de la promoción de algunas vocaciones a la promoción de todas las vocaciones. O crecemos juntos o no crece nadie.

3. Una pastoral propuesta a todos: de la propuesta a los «nuestros» a la propuesta a todos. Dios no hace acepción de personas.

4. Una pastoral de la esperanza audaz: del miedo a la valentía. Dios es novedad y futuro.

5. Una pastoral de fuertes convicciones: de la incertidumbre/timidez a la seguridad. En cada persona hay un don original de Dios.

6. Una pastoral del servicio a la persona concreta: del reclutamiento al cuidado de la persona. Toda persona es llamada a discernir y a realizar el proyecto de Dios.

7. Una pastoral de la Iglesia local: de «importar vocaciones» a cultivar los dones que toda Iglesia posee. El Señor sigue llamando en cada Iglesia y en cada lugar.

8. Una pastoral sistemática: de experiencias puntuales a itinerarios de educación vocacional. Quien está buscando necesita ayudas apropiadas. 
9. Una pastoral comunitaria: de acciones individuales a una acción coral. Toda la comunidad para todas las vocaciones, en todas las etapas de la vida.

10. Una pastoral crítica y creativa: de la "patología del cansancio», sobre todo de los presbíteros y consagrados, a un «nuevo impulso creativo» testimonial. La pastoral vocacional tiene una dignidad y una posición natural de centralidad y síntesis en el ámbito de la pastoral de la Iglesia, pastoral entendida como «mediación de la salvación de Dios» para cada persona. 